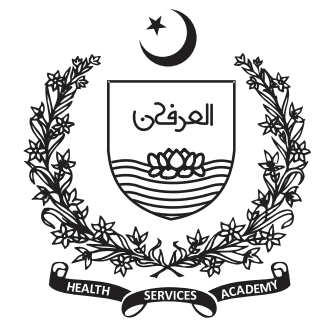

${ }^{1}$ Helping Hand Institute of Rehabilitation Science, Mansehra, Pakistan

Corresponding Author: Email:

Keramat Ullah Keramat karamatjee@yahoo.com

\section{Patients' Satisfaction with Physiotherapy Services for Musculoskeletal Disorder}

\author{
Keramat Ullah Keramat ${ }^{1}$, Abdul Haseeb Bhutta ${ }^{1}$, Misbah Binte Ilyas ${ }^{1}$
}

\section{Abstract}

Background: Patient centered approach is the cornerstone in health care facility. Therefore, patient satisfaction is of utmost importance. Factors related to satisfaction of patient in connection with physiotherapy practice are not evaluated. The purpose of this retrospective survey was to evaluate satisfaction of patient receiving physiotherapy for their musculoskeletal disorders at Helping Hand institute of Rehabilitation sciences Khyber Pakhtoon Khawa Mansehra, Pakistan

Methods: A retrospective survey of 200 male and female patients in the range of 18 to 80 years old was conducted in 2019 for the patient who had availed the services between 2017 and 2018. These patients were recruited through simple random sampling only to refrain from biasness. Keeping in mind the requirement of this survey the Med Risk Instrument Patient Satisfaction questionnaire was modified and was translated in Urdu.

Results: The retrospective survey of 200 patients of a median age 46 with musculoskeletal conditions 46. According to the survey among the abovementioned recipients $67 \%$ were with the opinion of highly satisfied with the way they have been facilitated and $32 \%$ of recipient fall under the term moderate satisfaction. With $\mathrm{P}$-value $<0.001$

Conclusion: Our study reveals that there is higher customer satisfaction from the skill of physiotherapist but the follow up exercise plan at home is considered worthless by the recipient. Physiotherapy provides more relish to middle aged and younger adults as compare to the older ones. Similarly, the results derived manifest female recipient satisfaction at higher level than male. The panorama of research exhibits that general contentment of patients is at higher level.

Keywords: Musculoskeletal disorders, patient satisfaction, physiotherapy, rehabilitation services

\section{Introduction}

$\mathrm{P}$ atient's care and patient satisfaction is getting prominent in health care domain. In evidencebased Physiotherapy patient's view about health is one of the three prime keys. Level of contentment of patient regarding services of physiotherapist can be evaluated by feedback about their treatment. Physiotherapist can evaluate their quality of work and services in patient care through this feedback. Patient's quality of life is directly related to their contentment regarding their physiotherapist 
and their treatment. This data is also useful for estimating the level of perfection in health care facility(1).

Patient oriented approach is making its way in health care. Cooperation between patient and physiotherapist regarding the specific disease, its understanding and expected results of post treatment plays pivotal role. Health care approach is considered worthy in research practices. But on the other hand patient's approach towards care plan cannot be neglected. It is as important as the behavior of clinician towards patient and his disease(2).

The term patient satisfaction cannot be simply defined as it is perceived; it is a complex phenomenon which depends on multiple factors but its importance in respect of organizational setup is divine. Organizations which are involved in provisions of health care in a competitive environment face many challenges to prove their quality services in terms of satisfying patient needs. Level of patient contentment is one of prime factor for such organizations to make them superior to their competitors in market. Higher level of patients satisfaction results in enhancing quality of service, further improvement in learning, positive influence on agenda development and increase chances to avail further opportunities(3). Evidences have proved that hospitals which are involved in provisions of multiple services can evaluate patient satisfaction for a single service. There are multiple factors which influence patient satisfaction either in a negative or positive sense. One of these is the satisfaction of staff members involved in respective service leaves positive impact on patient satisfaction, the other one is perception of the patient about hospital, treatment plan, providers' behavior and quality of service. It always happens that a patient comes not only with a problem but also with an opinion, and it's the overall behavior, treatment and level of relief that strengthens or weakens the already adopted opinion $(4,5)$.

Whenever patient satisfaction needs to be evaluated it must be cleared that patient satisfaction is composed of two domains one is patient satisfaction with treatment of Physical therapy and the other one is patient satisfaction with outcome. Both these entities are influenced by different factors, patient satisfaction outcome is referred to result of Physiotherapy treatment in terms of relieving symptoms and the other one satisfaction with quality of care in terms of facilities provided(6). This study however evaluates both domains of satisfaction of patient with Physical therapy. The purpose of this study is to evaluate patient satisfaction level with Physical therapy services provided by HHIRS and to discover factors influencing patient level of contentment to further improve quality services in HHIRS.

\section{Methodology}

This retrospective survey was conducted to evaluate patient satisfaction level with Physical therapy services on 200 patients of male and female in equal proportion and age ranging from 18 to 80 years. Simple random sampling was done to choose these patients by applying inclusion exclusion criteria. Both gender patients who were enrolled in Helping hand Institute of rehabilitation sciences from June 2017 to June 2018 were included in the study. Meanwhile patients who could not fill the questionnaire themselves either due to illiteracy or mental disability were excluded. Modified MRPS Questionnaire was used and translated into Urdu for better understanding of the patients. Keeping in mind the patient convenience very simple and comprehend able questionnaire was constructed, similarly the questions obvious to threat the cultural values were discarded. To contact the patients, HHIRS record was used. So the data was extracted and collected verbally by the researchers. In case of any ambiguity and confusion further help was provided and after taking verbal consent, data was collected by the researchers. The information collected from the patients being facilitated with physiotherapy during June 2017 to June 2018. Only 120 patients responded at first attempt of this retrospective survey out of which 76 were male and 44 were females. Additional 80 patients were approached for this survey to meet the number 200.

\section{Results}

Data were analyzed using SPSS version 21. Percentage and frequencies were computed for replies to each question. A total of 200 patients participated with median of age (IQR) 46 (27). Questionnaire was comprised of four parts mainly revolving around the details of patient satisfaction with the services provided, level of contentment with the physiotherapy practice, how much follow ups were retained, what kind and level of care was provided and the outcome of the treatment. Out of 200 participants $50 \%$ were male and $50 \%$ were females that were divided into 
three categories for the sake of better understanding and convenience such as young adults were with age of 18 to 38 years, middle adults 39 to 54 and older adults came under the heading of more than 55 years of age with the ratio of $33 \%, 33.5 \%$ and $33.5 \%$ respectively. Detail shown in table 1.

Table 1. Distribution of patients with respect to age group

\begin{tabular}{|c|c|c|c|c|}
\hline AGE GROUP & $\begin{array}{l}\text { Highly } \\
\text { Satisfied }\end{array}$ & Satisfied & Dissatisfied & $\begin{array}{c}\text { Strongly } \\
\text { dissatisfied }\end{array}$ \\
\hline $\begin{array}{c}\text { YOUNG } \\
\text { ADULTS } \\
(18-38)\end{array}$ & $72.70 \%$ & $25.80 \%$ & $1.50 \%$ & $0 \%$ \\
\hline $\begin{array}{c}\text { MIDDLE } \\
\text { AGE } \\
\text { ADULTS } \\
(39-54) \\
\end{array}$ & $73.10 \%$ & $26.90 \%$ & $0 \%$ & $0 \%$ \\
\hline $\begin{array}{c}\text { OLDER } \\
\text { ADULTS } \\
\text { (>55 YEARS) }\end{array}$ & $67.00 \%$ & $31.50 \%$ & $1.50 \%$ & $0 \%$ \\
\hline
\end{tabular}

Cross tabulation test in SPSS version 21 was applied statistically it was shown that females were highly satisfied as compared to men where male were moderately satisfied, only three men were dissatisfied with the services. Meanwhile no female patient reported dissatisfaction with the services.

According to this survey patients were found highly satisfied $67 \%$, satisfied $32 \%$ which comes under moderate satisfaction. Female patients highly satisfied $79 \%$, satisfied $21 \%$ whereas male patients highly satisfied $55 \%$ and satisfied $42 \%$.Younger adults highly satisfied $73.80 \%$, middle aged adults $74 \%$ and older adults $51.60 \%$. with chi square 14.29 and p-value, $<0.001$ detail shown in table 2 . Responses to the key question summarized in table 3

Table 2. Overall gender wise responses

\begin{tabular}{|c|c|c|c|c|c|c|}
\hline 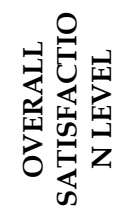 & 恶焉 & 焉 & 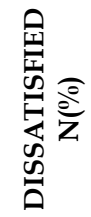 & 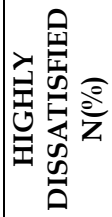 & $\mathrm{X}^{2}$ & 泾 \\
\hline MALE & $\begin{array}{c}55 \\
(55 \%)\end{array}$ & $\begin{array}{c}42 \\
(42 \%)\end{array}$ & $\begin{array}{c}3 \\
(3 \%)\end{array}$ & $\begin{array}{c}0 \\
(0 \%)\end{array}$ & \multirow{2}{*}{14.29} & \multirow{2}{*}{$\begin{array}{c}< \\
0.001\end{array}$} \\
\hline FEMALE & $\begin{array}{c}79 \\
(79 \%)\end{array}$ & $\begin{array}{c}21 \\
(21 \%)\end{array}$ & $\begin{array}{c}0 \\
(0 \%)\end{array}$ & $\begin{array}{c}0 \\
(0 \%)\end{array}$ & & \\
\hline $\begin{array}{c}\text { ALL } \\
\text { PARTIC } \\
\text { IPANTS }\end{array}$ & $\begin{array}{c}134 \\
(67 \%)\end{array}$ & $\begin{array}{c}63 \\
(32 \%)\end{array}$ & $\begin{array}{c}3 \\
(1.5 \%)\end{array}$ & $0(0 \%)$ & & \\
\hline
\end{tabular}

Table 3. Responses of participants to key questions

\begin{tabular}{|c|c|c|c|c|c|}
\hline $\begin{array}{l}\text { SATISFACTION } \\
\text { WITH OFFERED } \\
\text { SERVICES }\end{array}$ & 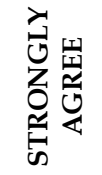 & 斵 & Z兄 & 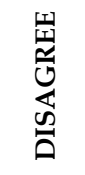 & 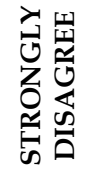 \\
\hline $\begin{array}{l}\text { 1. Schedule of } \\
\text { appointment was } \\
\text { convenient for } \\
\text { patient }\end{array}$ & $39 \%$ & $54 \%$ & $4 \%$ & $2.50 \%$ & $0 \%$ \\
\hline $\begin{array}{l}\text { 2. Appointment } \\
\text { started when } \\
\text { patient arrived } \\
\text { without any } \\
\text { further due }\end{array}$ & $31.00 \%$ & $\begin{array}{c}50.50 \\
\%\end{array}$ & $16 \%$ & $2.50 \%$ & $0 \%$ \\
\hline $\begin{array}{l}\text { 3. Updates to } \\
\text { exercise program } \\
\text { were made } \\
\text { frequently }\end{array}$ & $12.50 \%$ & $40 \%$ & $38 \%$ & $9.50 \%$ & $0 \%$ \\
\hline $\begin{array}{l}\text { 4. Recommend } \\
\text { HHIRS to friends } \\
\text { and relatives }\end{array}$ & $59 \%$ & $\begin{array}{c}28.50 \\
\%\end{array}$ & $8.50 \%$ & $4 \%$ & $0 \%$ \\
\hline $\begin{array}{l}\text { 5. If } \\
\text { physiotherapy is } \\
\text { needed again in } \\
\text { future will they } \\
\text { visit HHIRS }\end{array}$ & $59.50 \%$ & $\begin{array}{c}26.50 \\
\%\end{array}$ & $7 \%$ & $6.50 \%$ & $0.50 \%$ \\
\hline $\begin{array}{l}\text { 6. Experience at } \\
\text { HHIRS in regard } \\
\text { to satisfaction }\end{array}$ & $27.50 \%$ & $\begin{array}{c}41.50 \\
\%\end{array}$ & $13 \%$ & $17 \%$ & $1 \%$ \\
\hline
\end{tabular}

\section{Discussion}

This study was conducted in HHIRS Mansehra. Results reveal that $67 \%$ patients were highly satisfied and $32 \%$ were moderately satisfied with their Physical therapy treatment. Similar outcomes of satisfaction of $80.6 \%$ satisfaction level of patients with similar design were reported Jeddah Saudi Arabia(4). In Australia the satisfaction level reaches to $95 \%$ as declared by research studies(1). In Northern Europe, North America, United Kingdom and Ireland studies have shown highest levels of trust and patient compliance toward their Physiotherapists(7-9).Lagos based Nigerian study reported similar satisfaction as HHIRS Mansehra and dissatisfaction determinant was found to be waiting time on list(10). Currently, HHIRS has no waiting list and probably the satisfaction is high. When patient were evaluated about the physical therapy services the respectful behavior of the physiotherapist was highly appreciated and gave highest marks to Physical therapist respectful behavior, level of attention granted to them and the time allocated to them in their treatment tenure. Forbes and Nolan reported that attitude of the supervisor physiotherapist and the students behavior 
and effective communication are also the determinants of patient satisfaction level(11). This aspect is of particular importance since HHIRS provides clinical placement to the students. Similarly, a study by Casey L Peiris etal (2012), concluded in their paper that physiotherapist attention to recipient plays a vital role in the treatment because physiotherapist attention and respect were given more weightage than the treatment and amount of physiotherapy received. So our findings synchronize with the previous literature that patients are highly satisfied with their physical therapist conduct(12). Other studies have also claim that patients show greater satisfaction for physiotherapist time and attention rather to serve with quality equipment and parking facilities(5). Julia $M$ Hush et al (2103) also concluded in their study that patient satisfaction with Physical therapy can be maximized with good conduct of Physiotherapist as well as by addressing patients about diagnosis and plan of care that how it will work for them(7).

The survey in hand concluded that favorable and appreciate able behavior showed by the therapist satisfied the patient more and this make them ready for further visits to HHIRS again if they feel the need of any treatment. Some of the areas marked lower by the patients such as they constantly complain that their problem is not resolved fully and completely. In reality musculoskeletal conditions which are chronic in nature definitely needs greater time span to be fully recovered however patient expect that few sessions will be enough for them to make full recovery. A systematic review from 2011 stated that patients with acute musculoskeletal conditions show higher satisfaction than patients who are suffering from chronic conditions. So the reason behind lower marking about the recovery of musculoskeletal problem is chronic conditions which cannot be resolved in shorter time period. Previous studies have also shown that patients with acute musculoskeletal conditions are more satisfied than patients with chronic musculoskeletal condition which influences over all patient satisfaction outcome so is the case with our study(5). Further patients participated in this study stated that they were unable to make possible their regular follow ups so their problem took time to be resolved.

According to this survey patients strongly favour and recommended HHIRS visits to their kith and kin. This enlightens their satisfaction with physiotherapy treatment.
In this study female patients appear to be more satisfied with their therapy as compared to male patients .In previous studies it has been proved that female patients are greatly satisfied with physical therapy when compared to male population $(1,5)$. Still there are some more studies where male patients have shown greater satisfaction level as compared to female patients(13). Some other findings of this study ware that middle aged adults and young adults appeared to be more satisfied with physical therapy than the older adults. Previous studies which were done with regard to evaluate patient satisfaction showed greater satisfaction in older adults they stated that old people are more optimistic with their treatment and usually have low expectations hence show high satisfaction level with physical therapy treatment $(5,14)$.

Recently, a systematic review concluded that the factors effecting the patient satisfaction are clinical outcomes, physiotherapist features, patient features, physiotherapist-patient relationship, treatment features, and healthcare setting features(7). Therefore, a patient centered health care facility should focus on these aspects to improve patient satisfaction.

\section{Conclusion}

The results of this patient satisfaction qualitative survey concludes that patient who received physiotherapy services from HHIRS Mansehra in 2017 and 2018 were highly satisfied and factors which influence higher patient satisfaction are physiotherapist respectful conduct and dealing with patients in an empathetic manner. Moreover, patients have shown greater satisfaction not only with treatment facility but patients were also satisfied with their outcome. Middle adults and younger adults were more satisfied than older adults and female patients appeared to be more satisfied with their physical therapy treatment than male patients.

\section{References}

1. Hush JM, Yung V, Mackey M, Adams R, Wand BM, Nelson R, et al. Patient satisfaction with musculoskeletal physiotherapy care in Australia: an international comparison. Journal of Manual \& Manipulative Therapy. 2012;20(4):201-8.

2. Odole AC, Maruf FA. Agreement between patients' and clinical physiotherapists' expectations of care in public hospitals in Ibadan, Nigeria. International journal. 2014;7(1):211.

3. Heje HN, Vedsted P, Olesen F. General practitioners' experience and benefits from patient evaluations. BMC family practice. 2011;12(1):116. 
4. Devreux IC, Jacquerye A, Kittel F, Elsayed E, Al-Awa B. Benchmarking of patient satisfaction with physical rehabilitation services in various hospitals of Jeddah. Life science journal. 2012;9(3):73-8.

5. Tennakoon T, de Zoysa P. Patient satisfaction with physiotherapy services in an Asian country: A report from Sri Lanka. Hong Kong Physiotherapy Journal. 2014;32(2):79-85.

6. Casserley-Feeney SN, Phelan M, Duffy F, Roush S, Cairns MC, Hurley DA. Patient satisfaction with private physiotherapy for musculoskeletal pain. BMC musculoskeletal disorders. 2008;9(1):50.

7. Rossettini G, Latini TM, Palese A, Jack SM, Ristori D, Gonzatto $S$, et al. Determinants of patient satisfaction in outpatient musculoskeletal physiotherapy: a systematic, qualitative meta-summary, and meta-synthesis. Disability and Rehabilitation. 2020;42(4):460-72.

8. O'Mahony N, Blake C. Musculoskeletal triage: The experiences of advanced practice physiotherapists in Ireland. Physiotherapy Practice and Research. 2017;38(1):7-16.

9. Fennelly O, Blake C, FitzGerald O, Breen R, O'sullivan $\mathrm{C}$, O'mir $\mathrm{M}$, et al. Advanced musculoskeletal physiotherapy practice in Ireland: A National Survey. Musculoskeletal care. 2018;16(4):425-32.

10. Odumodu IJ, Olufunlayo TF, Ogunnowo BE, Kalu ME. Satisfaction with services among attendees of physiotherapy outpatient clinics in tertiary hospitals in Lagos State. Journal of Patient Experience. 2019:2374373519847370.

11. Forbes DR, Nolan D. Factors associated with patientsatisfaction in student-led physiotherapy clinics: A qualitative study. Physiotherapy theory and practice. 2018;34(9):705-13.

12. Peiris CL, Taylor NF, Shields N. Patients value patienttherapist interactions more than the amount or content of therapy during inpatient rehabilitation: a qualitative study. Journal of Physiotherapy. 2012;58(4):261-8.

13. Medeiros FCd, Costa LOP, Oliveira NdFC, Costa LdCM. Satisfaction of patients receiving physiotherapy care for musculoskeletal conditions: a cross-sectional study. Fisioterapia e Pesquisa. 2016;23(1):105-10.

14. Ferrand $Y B$, Siemens J, Weathers D, Fredendall LD, Choi Y, Pirrallo RG, et al. Patient Satisfaction With Healthcare Services A Critical Review. Quality Management Journal. 2016;23(4):6-22. 